\title{
SIMULATION MODEL BASED ON REGIONAL DEVELOPMENT AND VIRTUAL CHANGES
}

\author{
Petr Dlask
}

\author{
Czech Technical University in Prague, Faculty of Civil Engineering, Department of Economics and \\ Management in Civil Engineerig, Czech Republic \\ correspondence: dlask@fsv.cvut.cz
}

\begin{abstract}
This paper reports on change as an indicator that can be provide more focused goals in studies of development. The paper offers an answer to the question: How might management gain information from a simulation model and thus influence reality through pragmatic changes. We focus on where and when to influence, manage, and control basic technical-economic proposals. These proposals are mostly formed as simulation models. Unfortunately, however, they do not always provide an explanation of formation changes. A wide variety of simulation tools have become available, e.g. Simulink, Wolfram SystemModeler, VisSim, SystemBuild, STELLA, Adams, SIMSCRIPT, COMSOL Multiphysics, etc. However, there is only limited support for the construction of simulation models of a technical-economic nature. Mathematics has developed the concept of differentiation. Economics has developed the concept of marginality. Technical-economic design has yet to develop an equivalent methodology. This paper discusses an,alternative approach that uses the phenomenon of change, and provides a way from professional knowledge, which can be seen as a purer kind of information, to a more dynamic computing model (a simulation model that interprets changes as method). The validation of changes, as a result for use in managerial decision making, and condition for managerial decision making, can thus be improved.
\end{abstract}

KEYWORDS: change; qualitative strategy; economic development; change indicator; simulation; innovation; decisions; problem solving.

AMS Mathematics Subject Classification: 03B80, 28E15, 91B30.

\section{INTRODUCTION TO THE MODELLING OF CHANGE, AND A RATIONALE FOR IT}

Technical-economic problems are usually described by deterministic parameters (drawings, maps, photos, statistical data, etc.) Many intrinsic problems are described in [1] p. 139, and they manifest dynamic behaviour [4, 5]. With the currently existing methodologies and models that are used (i.e. based on statistical data), it is often risky to predict future developments (see the commentary on Figure 4). The future and future developments are important in all exemplary situations - technical changes (variants), economic measures (management, control, steering), innovation, development, evaluation of alternative solutions, and the like. In the modern methodology for managing such situations, it is claimed that expert knowledge of potential change (mostly based on simulations) might enable alternative approaches to be modelled and evaluated. Significant progress on the topic of change [5, 44] has been achieved through simulation models [22]. These models have shown their relevance in project activities, in assisting, for example, environmental managers, architects, urban planners and engineers. General possible ways to obtain information from a simulation model are presented in section 3.1, and are visualised in Figure 6. A practical example is shown in Figure 5, and is evaluated in Table 4 For the sake of brevity, the authors do not present the simulation curves for the activities (model elements) referred to in Table 4 The main focus is on comparing the efficiency of managerial interventions changes, see $\S 4$ especially $\S 4.2$.

\subsection{Details FOR LONG-TERM CHANGE AS AN OBJECTIVE - A HISTORICAL PERSPECTIVE}

Figure 1 shows as an illustration the development of the building stock in Pribram, a town in Central Bohemia, in the period 1648-1898 (the imagination of the reader will intuitively find other examples in his own field). The buildings and the surface plots are a quantitative indicator of development. However, for ex-ante information it is important to consider expected change for determining the upcoming future. The development in Figure 1 is characterized from 1648 by agricultural farm buildings and craftsmanship, and later, until 1898, the development is characterized by buildings for small manufacturing. Figure 1 seeks to address the questions: a) What method can be used to compare the development over time, and b) What model is suitable for addressing the main development indicators? Development proposals are mostly related to regional productivity [33], and are a prerequisite for consistent linear consumption. This precondition was 


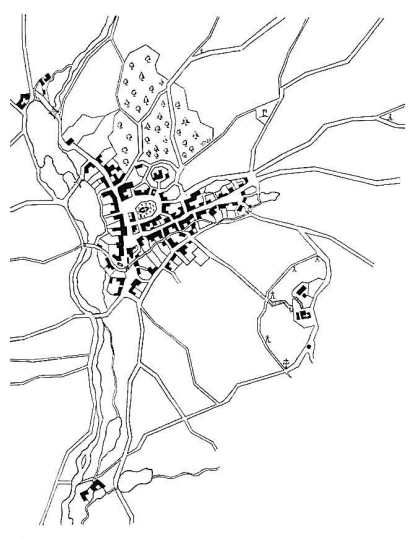

1648

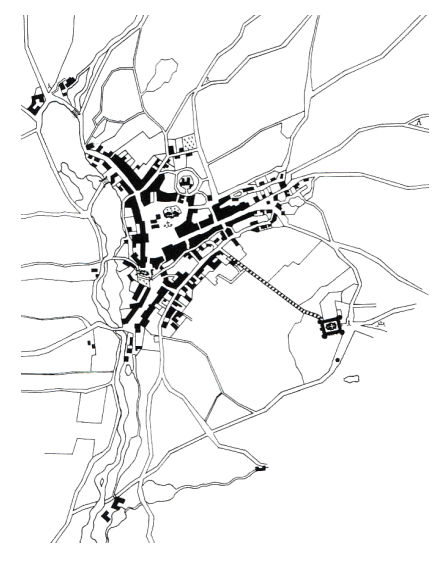

1798

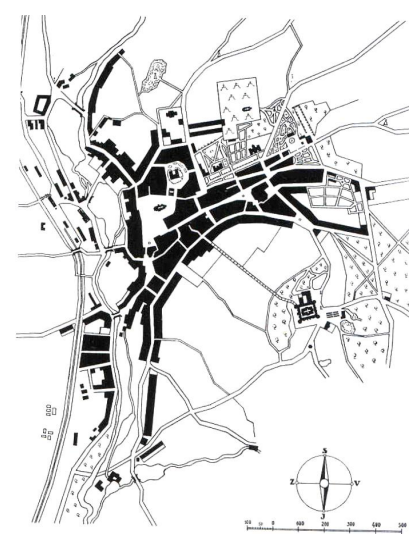

1898

Figure 1. Growth of Pribram, a town in Central Bohemia, quantitative data $\boldsymbol{A}^{Q}$ for years 1648,1798 and 1898. Source: from old engravings F. Frýba, Architekt 7-8, 1998.

\begin{tabular}{lllrrr}
\hline Built-up area in ha & $\mathbf{1 9 4 8}$ & $\mathbf{1 9 5 8}$ & $\mathbf{1 9 6 7}$ & $\mathbf{1 9 8 2}$ & $\mathbf{1 9 9 6}$ \\
\hline Continuous built-up area & 13.6 & 29.35 & 26.73 & 33.74 & 34.61 \\
Discontinuous built-up area & 10.2 & 33.78 & 107.82 & 121.69 & 133.36 \\
Family houses & 27.78 & 18.43 & 48.77 & 89.23 & 91.29 \\
Built-up area and greenery & 31.68 & 33.04 & 110.39 & 134.74 & 138.57 \\
Industry & 23.03 & 25.91 & 97.18 & 185.47 & 208.57 \\
Roads & 31.43 & 27.31 & 43.24 & 68.79 & 77.41 \\
\hline
\end{tabular}

TABle 1. Evaluation of aerial photos of Pribram, a town in Central Bohemia. Cumulative Values in [ha].

\begin{tabular}{lrrrr}
\hline Built-up area in ha & $\mathbf{1 9 5 8}$ & $\mathbf{1 9 6 7}$ & $\mathbf{1 9 8 2}$ & $\mathbf{1 9 9 6}$ \\
\hline Continuous built-up area & 15.75 & -2.62 & 7.01 & 0.87 \\
Discontinuous built-up area & 23.58 & 74.04 & 13.87 & 11.67 \\
Family houses & -9.35 & 30.34 & 40.46 & 2.06 \\
Built-up area and greenery & 1.36 & 77.35 & 24.35 & 3.83 \\
Industry & 2.88 & 71.27 & 88.29 & 23.1 \\
Roads & -4.12 & 15.93 & 25.55 & 8.62 \\
\hline
\end{tabular}

TABle 2. Evaluation of aerial photos Pribram, Central Bohemia. Differences in Cumulative Values in [ha].

disputed in a paper by Kondratieff [28] in the last century. Investment, physical capital and infrastructure are the main pillars of economic growth in neoclassical economics, and on this topic Solow's work 39] has had a dominant influence. The neoclassical theory is mostly built on productivity concepts. Economic development and classical mathematics [47] promoted change and derivatives as terms stated for quantitative and qualitative model descriptions. The IMD (Institute for Management and Development) defines competitiveness as an environment that sustains more values; and a ranking of states on this is presented in [50. The example in Figure 1 presents long-term stagnation lasting approximately 250 years, and we are looking for early indicators of positive development. The European Community [13], [14] has adopted the concept of competitiveness as a key indicator for the ability to generate output and employment as a basis for long-term economic growth. There is a certain imbalance in the theory of macroeconomic development, on the one hand, and individual microeconomic developments, on the other. Microeconomic units such as cities, townships and villages (and, in general, all technical design) have to evaluate actually existing projects and strategies.

\section{AIMS}

The explicit purpose of this paper is to predict the impact of technical-economic changes. Subsequently, simulation is presented as an emulative option in designing new solutions. Most man-made objects are broken down into a Long memory of quantitative $\boldsymbol{A}^{Q}$ datasets (presented as knowledge: maps, technical drawings, statistics, etc., Figure 1 serves as an example) and qualitative datasets $\boldsymbol{A}^{Q^{\prime}}, \boldsymbol{A}^{Q^{\prime \prime}}, \boldsymbol{A}^{Q^{\prime \prime \prime}}, \ldots$ (to be understood as sets of changes to previous technical 


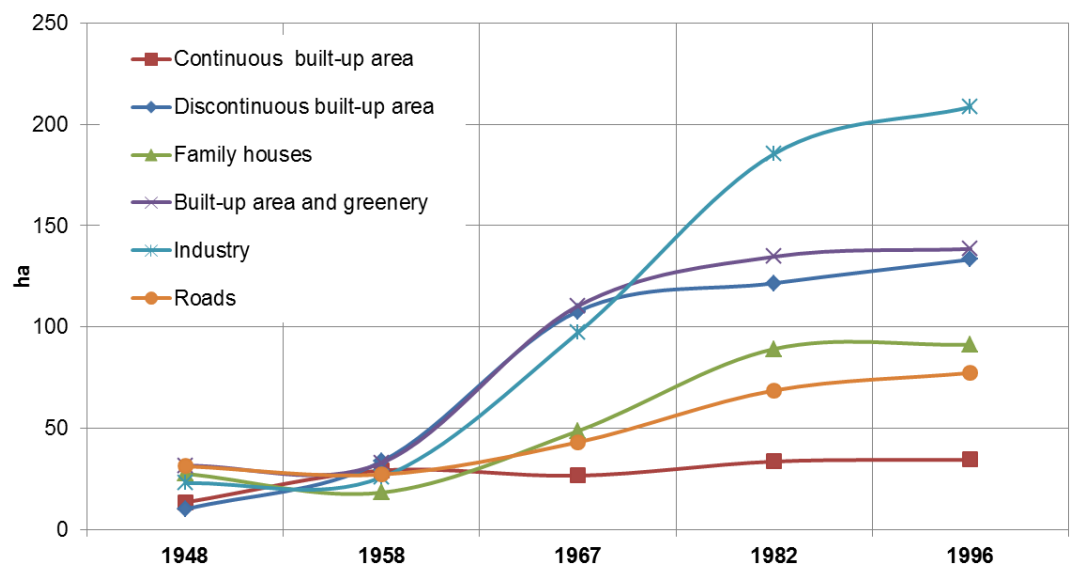

FigURE 2. Quantitative evaluation of aerial photographs. Transfer to cumulative volumes [ha].

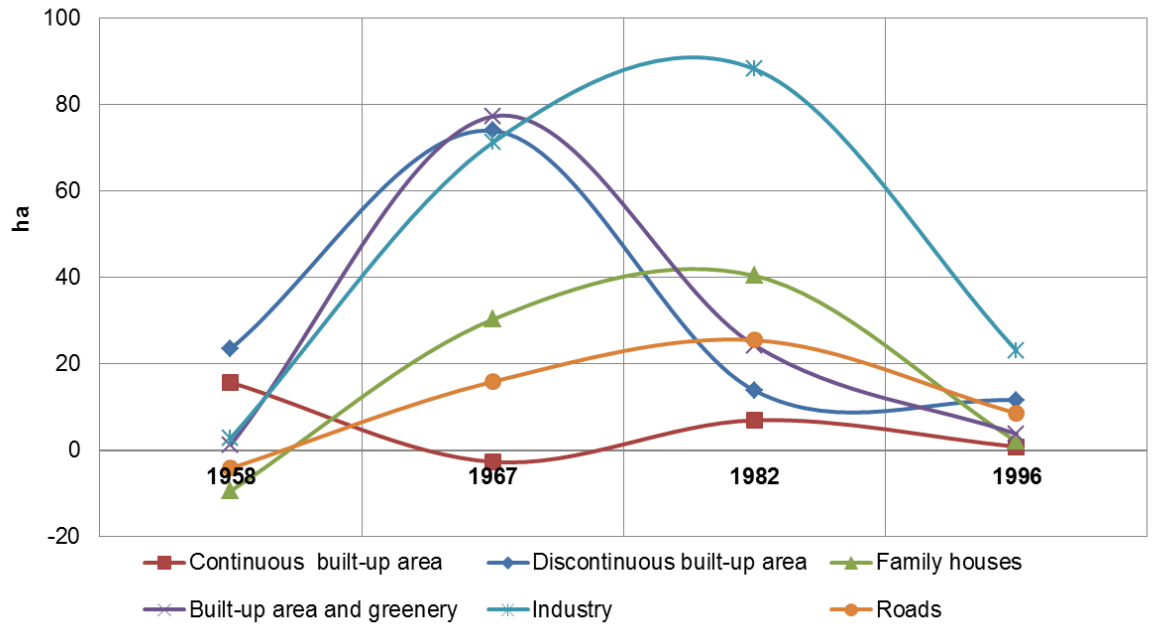

FiguRE 3. Changes derived from cumulative [ha] volumes of the aerial photographs presented in Figure 2 .

matters). The current state of knowledge both displays and gives material substance to past decisions $[3]$. The aim is to construct such a factual content, with innovation and new solutions suggesting the nature of change. According to Schumpeter [40, innovation is in essence an instigator of economic change. This eminent author deals with the macroeconomic impact of innovation. His approach harmonizes with Kondratieff wave theory [28. Our example in Figure 1 relates the first wave to silver mining in the Pribram region. The second wave was initiated in this region by lead mining. The third wave was formed on the basis of uranium mining soon after World War II.

\subsection{Misleading DATA FOR QUAlitative PROPOSALS - THE CASE OF MAPS AND AERIAL PHOTOGRAPHS}

Aerial data analyses of built-up areas (as seen in Tables 1 and 2 are presented in Figures 2 and 3 , and a prognosis is presented in Figure 4. Essentially, we are still handling "statistical" ex-post facts. Even modern aerial and satellite images represent nothing more than quantitative retrospective data. Converting them to a time series perspective is very often misleading. Figure 4 illustrates this mistaken viewpoint. On the one hand, the coefficient of determination is denoted by a very high $\boldsymbol{R}^{2}$; while, on the other, the trend prognosis is wrong and cannot be confirmed.

The aim of this paper is to conceive a model of simulation as a construct sufficiently plausible to serve as a development perspective - in strategic terms. The distinctive contribution to this will be found in the work of Palermo and Ponzini [32, which is a documented critique of the eclecticism and abstraction characterising the main trends in current planning theory.

Figure 2 shows resulting data derived from aerial photo images (see Table 1 and 2 in definite continuation of the development given in Figure 1 B Both data sources, maps and aerial photographs, contain only quantitative knowledge, such as $G_{\text {map }}\left(\boldsymbol{A}^{Q}\right)$, which is basic for constructing a node- or edge-oriented graph, where $\boldsymbol{A}^{Q}$ are sets of relevant quantitative inputs [11. Details relevant to the construction of a simulation 


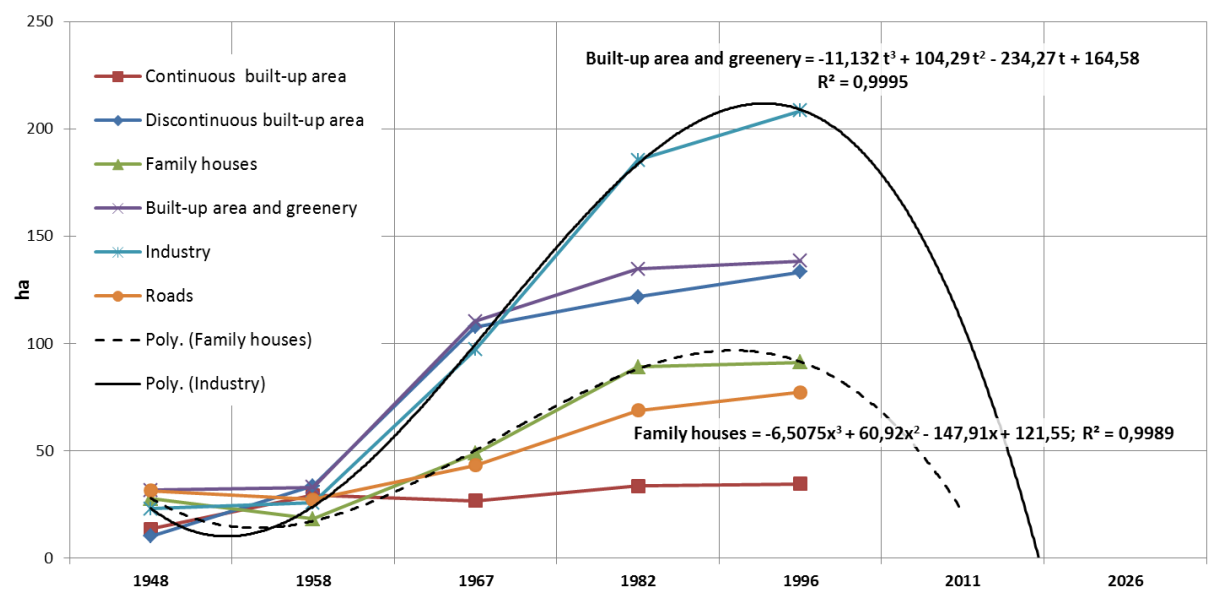

FiguRE 4. Misleading trend line forecasts on the basis of aerial data. The situation that occurs if there is not a functional model.

model are mentioned in Section 3, and a regional development interpretation is presented in Figures 5 and 6 .

Figure 2 shows the growth performance since 1958, followed by a sharp increase in built-up areas. Cessation of growth is evident from the aerial photographs taken in 1982, and in 1996 a stagnant region is shown, the data being presented in Appendix Tables 1 and 2 . The cumulative values presented in Figure 2 give a relatively optimistic impression of the growth, and send out late warnings about the imminent subsequent slowdown. The indications on the basis of changes presented in Figure 3 are significantly comprehensive. These curves are derived from data for Figure 2 and provide early warnings of stagnation, already in evidence by 1967. There were exceptions in the industrial areas, where central planning attempted to stimulate the regional economy by investment. Despite this investment, however, the stagnation reappeared in 1982 . This development collapsed definitively in 1996.

The method of forecasting for 1996 visualised in Figure 4 requires new stimuli to deal with the substance of the problem. The approach does not indicate changes at an early stage of information. An understanding of the problem as dynamic change management has been proposed by a number of authors as a reasonable improvement [4, 16, 18, 25].

\section{Simulation AND REgional DEVELOPMENT METHODS FOR GROWTH}

Low annual growth rates can be raised as a planning question on how to stimulate development. Development linked to productivity and trade is presented in Porter [33], and his hypotheses are supported by statistics (see the example in Figures 2 and 3 . In his studies, rigorous designation of certain production resources as innovations, technology and organization of the production process remain as ex-ante findings. The deeper qualitative support and ex-ante assertions are rather restrained [51].

\subsection{AN APPROACH ON THE BASIS OF QUANTITATIVE DATA}

The problem of development viewed in Figures 2 and 3 from 1996 as a time point requires a dynamic approach for the construction of an ex-ante perspective. Statistical reviews are not incorporated into the account; details are mentioned e.g. in the Introduction to [8]. A number of authors have proposed that the problem should be understood as a problem of dynamic change management [4, 16, 18, 25].

An example for a regional initiative in development is presented in Figure 5. Any activity has a quantitative interpretation and a qualitative interpretation, a review being offered in Table 3 It is not easy to define the parameters for a particular case; let us say, a specific regional case of desired development [9] and [21]. This paper embraces methodological evolution; see the OECD Environmental Outlook to 2030, and in [30, Table 7.3] or the general presentation in [31]. An extensive description is given in [1]. The quantitative data $\boldsymbol{A}^{Q}$, given in Figure 2, do not enable the appropriate ex ante view. An example is given in Figure 4

\subsection{ThE CONDITION OF QUANTITATIVE AND QUALITATIVE KNOWLEDGE FOR A SIMULATION MODEL}

Simulation might offer us more inspiring support. Standing back objectively, we are looking for indicators for quantitative $\boldsymbol{A}^{Q}$ and qualitative $\boldsymbol{A}^{s Q}, \boldsymbol{A}^{s 2 Q}$, $\boldsymbol{A}^{s 3 Q}, \ldots$ information. We mentioned the quantitative $\boldsymbol{A}^{Q}$ parameters related to Figure 2 above, and the qualitative $\boldsymbol{A}^{s Q}$ parameters as a desired interpretation outlined in Figure 3 . The background is well-known from Isaac Newton's Philosophiae Naturalis Principia 


\begin{tabular}{ccccc}
\hline Quantities & $\begin{array}{c}\text { Changes of Quantity } \\
\text { (speed) }\end{array}$ & $\begin{array}{c}\text { Acceleration } \\
\text { (Changes of speed) }\end{array}$ & $\begin{array}{c}\text { Effort, Energy } \\
\text { (necessary resources) }\end{array}$ & Remarks \\
\hline $\boldsymbol{A}^{Q}$ & $\boldsymbol{A}^{Q^{\prime}}$ & $\boldsymbol{A}^{Q^{\prime \prime}}$ & $\boldsymbol{A}^{Q^{\prime \prime \prime}}$ & Virtual indicators \\
\hline
\end{tabular}

TABLE 3. Chain of knowledge sets hierarchy and interpretation.

\begin{tabular}{|c|c|c|c|c|c|c|c|c|c|c|c|c|c|c|c|c|c|c|}
\hline \multirow{2}{*}{\multicolumn{2}{|c|}{ Segment / Set of Activities / A .... matrix }} & \multicolumn{4}{|c|}{ Segment I. } & \multicolumn{7}{|c|}{ Segmet II. } & \multicolumn{5}{|c|}{ Segment III. } & \multirow{2}{*}{$\boldsymbol{X}_{0}$} \\
\hline & & 1 & 2 & 3 & 4 & 1 & 2 & 3 & 4 & 4 & 6 & 7 & 1 & 2 & 3 & 4 & 5 & \\
\hline \multirow{4}{*}{ I. } & 1. Added Value Creation in Region & & & & 0,12 & & & & & 0,60 & 0,13 & & & & & & & 0,71 \\
\hline & 2. Credit Availability & $-0,4$ & & & & & & & & & & & & & & & & 0,5 \\
\hline & 3. (+) Capital Mobility & 0,22 & & & 0,04 & & & & & & & & & & & & & 0,58 \\
\hline & 4. Tech./Eco. Innovations & & 0,02 & 0,16 & & & & & & & & & & & & & & 0,48 \\
\hline \multirow{7}{*}{ II. } & 1. Housing and Housing Revitalization & & & & & & $-0,08$ & & & & & & & & & & & 0,6 \\
\hline & 2. Total Housing Fund & & & & & $-0,20$ & & $-0,60$ & 0,10 & & 0,16 & & 0,05 & 0,03 & & & & 0,59 \\
\hline & 3. Purchasing Power & & & & & & $-0,11$ & & & 0,20 & 0,19 & & & & & & & 0,77 \\
\hline & 4. Job Vacancies & & & & & & & & & 0,33 & $-0,22$ & & & & & & & 0,76 \\
\hline & 5. Middle Size and Large Enterprises (>200) & & & & & & & & 0,21 & & $-0,25$ & 0,16 & & & & & & 0,75 \\
\hline & 6. Small Enterprises & & & & & & 0,24 & & 0,06 & $-0,37$ & & 0,12 & & & & & & 0,64 \\
\hline & 7. Local Infrastructure & & & & 0,04 & & & & & 0,30 & $-0,32$ & & & & & & & 0,82 \\
\hline \multirow{5}{*}{ III. } & 1. Population in Production Age & & & & & & & & & & & & & $-0,3$ & & & & 0,73 \\
\hline & 2. Total Number of Inhabitants & & & & & & & & & & & & 0,05 & & -0 & 0,18 & & 0,82 \\
\hline & 3. Current Mortality & & & & & & & & & & & & & & & & $-0,1$ & 0,25 \\
\hline & 4. Immigration & & & & & & & & & & $-0,01$ & & & & & & $-0,6$ & 0,2 \\
\hline & 5. Social Securities & & & & & & & 0,08 & & & & & & & $-0,5$ & & & 0,5 \\
\hline
\end{tabular}

TABle 4. Interaction matrix $\boldsymbol{A}$ of regional development model, Segment I. - Capital, Segment II. - Housing, Jobs, Segment III. - Population and vector $\boldsymbol{X}_{t=0}$ of starting conditions. A more detailed explanation of interaction calculation is provided in [5]. For an evaluation of changes in this paper, the calculation technique is only informative. The diagonal of matrix A indicates the main application segments, the sub matrices above the diagonal indicate the main "forward" linkages, and the submatrix below the main diagonal indicates "feedback" interactions. Segments of the matrix are $\boldsymbol{A}=\left(\begin{array}{ccc}A_{I, I} & A_{I, I I} & 0 \\ A_{I I, I} & A_{I I, I I} & A_{I I, I I I} \\ 0 & A_{I I I, I I} & A_{I I I, I I I}\end{array}\right)$.

Mathematica, published in 1687, which introduces the first three individual parameters and their mechanical indicators mass, velocity and acceleration. The concept of energy was introduced later by Thomson (1807), and was calculated according to Leibniz as the product of the mass of an object and its velocity squared. Let us allow, in relation to Table 3 , the luxury of an example; a) the basic chain of the three hierarchical parameters has been known for more than 300 years, b) the first models of the Club of Rome $22]^{1}$ were worked out for thousands of variables.

The weak prognosis [51 made on the basis of the individual quantitative data indicated in Figure 4 is inadequate for management strategies. What is required is actual knowledge transformed into computational parameters.

If we use models like $\mathrm{AR}(1)$, there are uncertainties in the factual description of the modelled process, say: innovation, organization, production. Misleading results arise especially when applying polynomial forecast functions. Even for short periods of time, prognoses are often misleading. If we compare prognosis results of odd or even polynomial degree we see strongly disproportional results. In particular, an im-

\footnotetext{
${ }^{1}$ The purpose of The Limits to Growth was to explore how exponential growth interacts with finite resources.
}

proper rate of polynomial approximation could lead to misleading predictions.

In fact, without a priori knowledge, it is not possible to estimate the original source data (for example given in Figure 1 or in Figure 2, The mixing and filtering process is based on formulation (1), (3) and application by simulations (e.g. Figures 6,5 etc.).

\subsection{A GENERAL DESCRIPTION OF THE SIMULATION METHOD - MODEL MANAGEMENT}

The methodical interpretation and calculative model of any process passes through the formulation phase and can later be formulated at a difference level in the space of solutions $\Omega$. The core meta-knowledge basis is mentioned in Table 3 and indicators are identified as virtual.

In the scheme of Figure 6, the implemented knowledge $\boldsymbol{A}^{Q^{\prime}}, \boldsymbol{A}^{Q^{\prime \prime}}, \ldots$ about problem $\Omega$ is transferred to states and changes per time unit. Figure 5 presents the general scheme $G_{\text {int }}\left(\boldsymbol{A}, \boldsymbol{X}_{0}\right)$, which is converted into detailed interactions i.e. to the matrix $\boldsymbol{A}$ in Table 4. A detailed explanation is provided in [5].

There exists a starting situation (initial state) ${ }^{2}$

\footnotetext{
${ }^{2}$ In regional or urban development, a complex territory or region: starting standard of base year solution.
} 


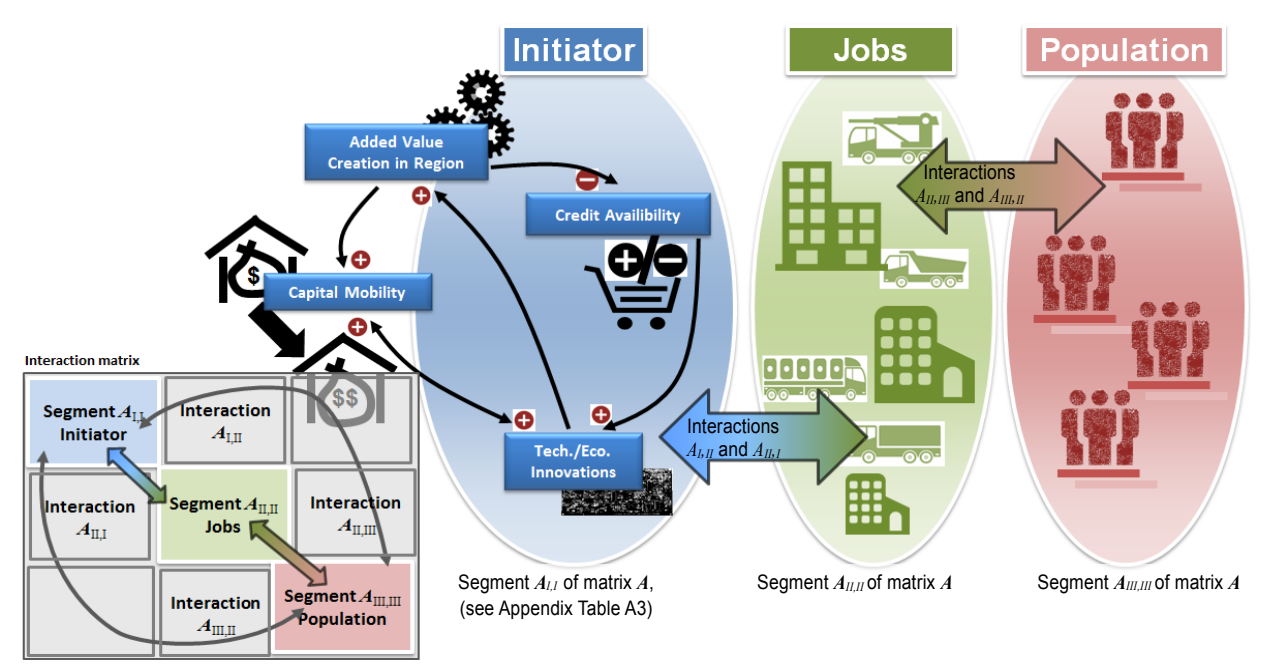

FIGURE 5. Simulation initiating development attributes for Segment I. Implementation into regional development scheme - Central Bohemia, town of Pribram. Segments: I. Capital, II. Jobs and Housing, III. Population; the full structure of matrix $\boldsymbol{A}$ is given in Table 4.

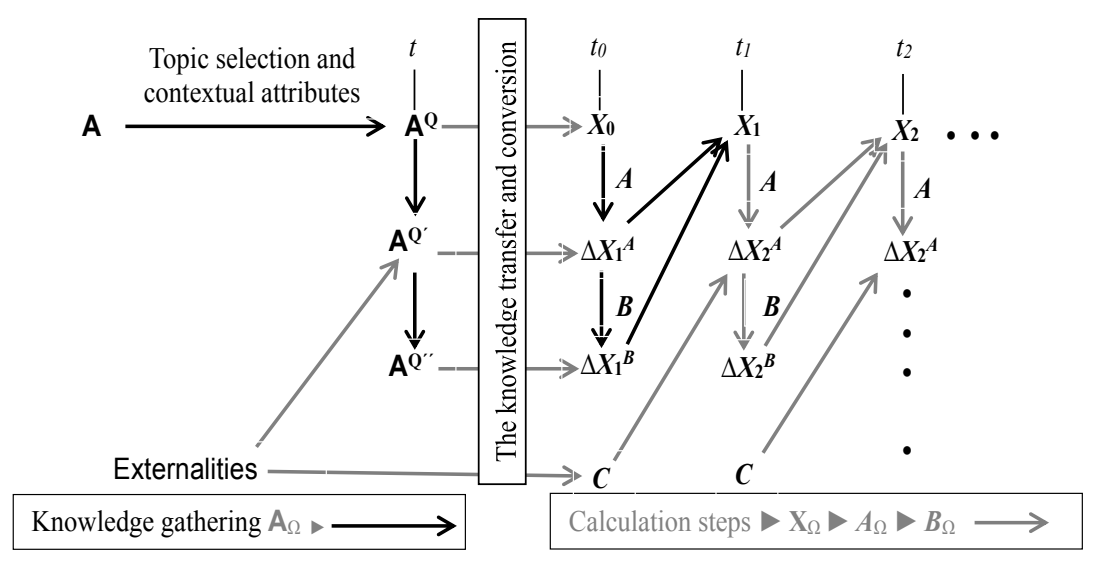

FiguRE 6. Scheme of parameter tracing: knowledge for issue $\Omega$ and creation of changes.

based on quantitative knowledge of elements $\boldsymbol{A}^{Q}$ at $t_{0}$ and their selection for $\boldsymbol{X}_{t=0}$ process matrix ${ }^{3} \boldsymbol{A}$ is based on influencing the intensities of changes $a_{i j}$ (equations (2), (2a)) and matrix $\boldsymbol{B}$ describing accelerations $b_{i j}$ as changes of matrix $\boldsymbol{A}$ (equation (3)). The resulting example in Figure 5 is the transformation of $\mathrm{A}_{\Omega}$ to calculation basis $\boldsymbol{A}_{\Omega}$ as $G_{\text {int }}\left(\boldsymbol{A}, \boldsymbol{X}_{0}\right)$. What is essential is the transformation of knowledge $\Omega$. There are several methods for transforming existing data (statistics, professional knowledge, etc.) to scaled data as $a_{i j}$, for details see [19]. In the calculation used in this paper, in $\$ 4$ preference is given to min-max normalization. Formula (1) maps data to the range $\left[x_{\min }, x_{\max }\right]$, for example to $[0,1]$ :

$$
x_{i}^{\prime}=\frac{x_{\max }-x_{\min }}{x_{\max \Omega}-x_{\min \Omega}}\left(x_{i}-x_{\min \Omega}\right)+x_{\min },
$$

where $x_{i}^{\prime}$ is the normalized value $x_{i}$ of original data

\footnotetext{
${ }^{3}$ Note that we distinguish matrices and vectors, written as $\boldsymbol{A}$, and sets, written as A.
}

attribute $\Omega$ mapped to a new range $\left[x_{\min }, x_{\max }\right]$.

The transformation provides a conversion of the original statistical data to comparable data given in Table 4 The main issue is to characterize the changes that bring proposed outputs, e.g., innovation, improvements. Attribute $\Omega$ is in fact based on knowledge set A.

The change of $\boldsymbol{X}_{t}$ for the time period $\Delta t$ is defined (general framework) as

$$
\Delta \boldsymbol{X}_{t+1}=\boldsymbol{A} \boldsymbol{X}_{t}
$$

and the new standard (i.e., prediction technique) after $\Delta t$ is given as

$$
\boldsymbol{X}_{t+1}=\boldsymbol{X}_{t}+\Delta \boldsymbol{X}_{t+1}
$$

where $\boldsymbol{A}$ is a matrix of evaluated interactions for $\Delta t$, and $a_{i j} \in\langle+1 ;-1\rangle$ are based on $(1), \boldsymbol{X}_{t}$ is a state vector of standards in time period $t$, selected from the set of quantitative activities $\boldsymbol{A}^{Q}$, and $\Delta \boldsymbol{X}_{t}$ is a 


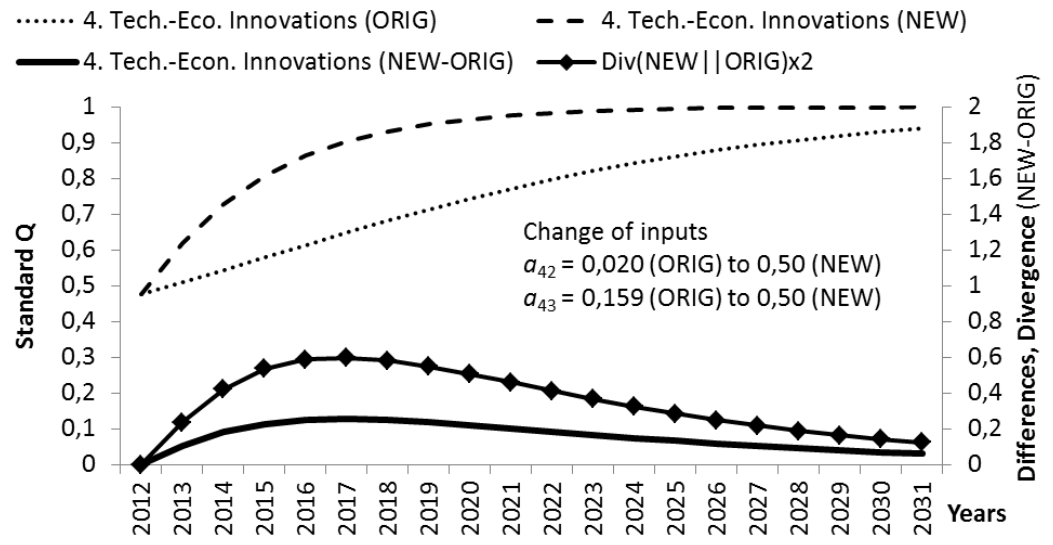

Figure 7. The simulation for element 4. T/E innovations based on Table 4 (ORIG), and the change in the situation after robust support through $a_{42}$ and $a_{43}(\mathrm{NEW})$; difference $\boldsymbol{g}^{D}=D(\cdot \| \cdot)$ is the bold line.

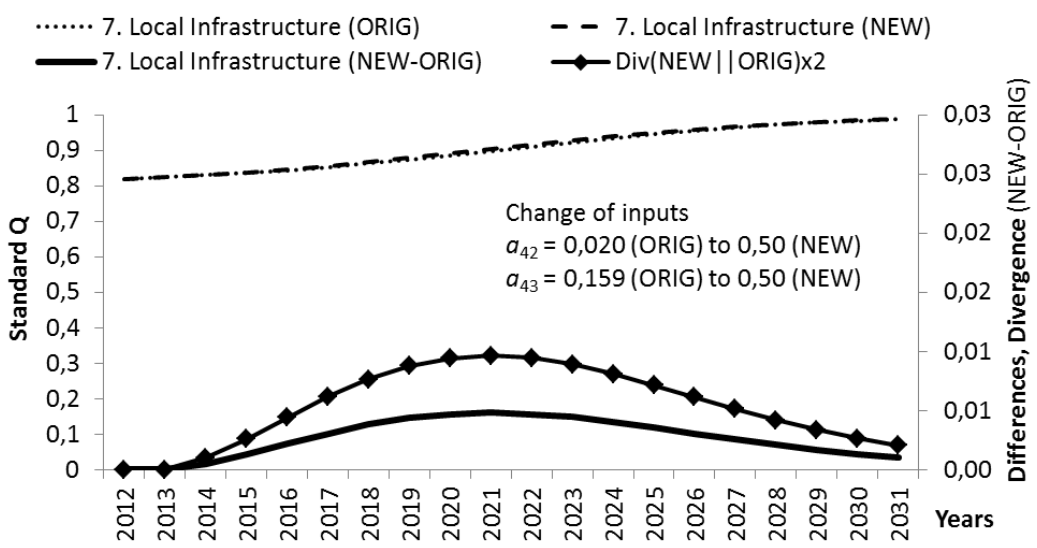

Figure 8. The robust support (increase $a_{42}$ and $a_{43}$ ) for element 4. T/E innovations, and its influence on element 7. Local infrastructure (as ORIG) and change (as NEW); the influence is recalculated as divergence - bold line.

vector of changes in the time period $t$. For more comprehensive simulation in the formation of changes it is appropriate to extend formulation (2) to

$$
\Delta \boldsymbol{X}_{t+1}=\boldsymbol{A} \boldsymbol{X}_{t}+\boldsymbol{B} \Delta \boldsymbol{X}_{t}+\boldsymbol{C},
$$

where $\boldsymbol{B}$ is a matrix of acceleration of changes related to matrix $\boldsymbol{A}$, quantified as amendment $b_{i j} \in$ $\langle-0.1 ;+0.1\rangle$ for particular $a_{i j}$ over time step $\Delta t$ and $\boldsymbol{C}$ is a vector of external influences; further details are given in [7].

The simulation model - example related to the Figure 5 is explained, and is divided into segments; the segmentation of default matrix $\boldsymbol{A}$ is shown in the Note to Table 4

\section{Results AND DisCUSSION - \\ EXAMPLES OF REGIONAL DEVELOPMENT}

The model presented in Figure 5 and the interaction Table 4 in the Appendix show the development mechanism for the region. For simplicity, it is the matrix
$\boldsymbol{B}=\mathbf{0}$. The simulation calculation uses an approximation procedure for ascertaining $\boldsymbol{X}(t)$, clarified in (1), (2) and in Kane (1972) in [25] or Holling (1978) in [22]. Dynamic simulation (there is more in Forester [15 18]) supports decision making [38, the comparison of variants, innovation proposals, and regional development planning. The dynamic modelling technique [7, 8, provides an understanding of functional requirements for future (ex-ante) development, and avoids difficulties already described in the comments about misleading forecasts presented in Figure 4

The procedure can improve decision making 34 36]. The simulation tool helps in decision making for long run validity, even for long life cycle assets, which indeed industrial and infrastructural projects [46] usually are, see [26] or [40]. Modern disputes about evaluation of decision data are presented in [24] and in regionally-focused sources [43] and [30. We will not address the issue of simulation techniques on the basis of software that are related to Figure 6 and Figure 5 Computational methods in this paper have been presented schematically by relations (2) and (3). 
Sophisticated solutions and various software packages for simulations are available commercially or as free SW. The key problem lies in evaluating the output data that is obtained.

\subsection{DivergenCy}

The problem of decision-making mentioned above is not to be seen as a short-term decision. The implied decision-making is to distinguish solutions in the context of a relative long time period. This paper states that we are looking for indicators of change for time series based on a simulation model as a set of source signals, i.e. as an economic time series about regional progress. Creation of variants, alternatives, strategies or innovations requires comparisons of one simulated time series with another.

Improvements in proposals (e.g. economic proposals technical solutions, design solutions) need an evaluation of their potential. We will calculate this differentiation as the divergence between time series e.g. ORIG $\mathrm{p}$ and NEW proposal q. Space $\Omega$ is the platform of all ex-ante simulations of the problem. The divergence on $\Omega$ is a vector, and is given as the function

$$
\boldsymbol{g}^{D}=D(\mathrm{p} \| \mathrm{q}): \Omega \rightarrow \boldsymbol{R}^{+},
$$

where $\boldsymbol{g}^{D}=D(\mathbf{p} \| \mathbf{q})$ is a function describing the distance of time series (proposals) p to $\mathrm{q}$.

In most situations we are looking for potential changes that may cause a positive response for further progress. We are looking for a solution which is able to compare a new solution with an existing original as $\boldsymbol{g}^{D}=D(\mathrm{ORIG} \| \mathrm{NEW})$.

If divergence has indicated priority over the original solution as

$$
\boldsymbol{g}_{\mathrm{ORIG} \| \mathrm{NEW}(1)}^{D} \geq \boldsymbol{g}_{\mathrm{ORIG} \| \operatorname{NEW}(2)}^{D}
$$

then there is a valid preference

$$
\operatorname{NEW}(1) \succ \operatorname{NEW}(2) \text {. }
$$

In other words, we seek the gradient of growth in problem space $\Omega$. In many fields of technical-economic applications, we need to compare proposed approaches and their results, e.g. benefits; states achieved, strategies, functionality of technical details, etc.

In some cases the evaluation may be supplemented by calculating the degree of similarity. In developing strategies, we need to compare data series by telling the degree of difference. In some studies, these functions are called distance measures or divergence measures [45].

\subsection{Discussion on Change PRoposals - REGIONAL PROGRESS EXAMPLE}

The calculation of distances for the given example in Figures 7 and 8 is based on differences. In Figure 6 . we observe that the structure of matrix $A$ is the main source of changes. The realistic improvements of $a_{i j}$ are potential for improvements (innovations, progress).
Whatever changes are desirable need to be supported technically, and materially. Our example is about induced investments, and is focused in Figure 7 on element 4. Tech./Econ. Innovations. More details are available in Table 4 Suppose we decide to improve regional development by escalating Credit availability $\left(a_{42}\right)$ and Capital mobility $\left(a_{43}\right)$, as given in Appendix Table 4. The simulation results for 20 time periods are (for its own supported element 4. T/E innovations) given in Figure 7, and they decrease over the long term. Further, it is evident that the idea of strengthening target element 7. Local Infrastructures by the proposed change was also not successful. The increases in Figure 8 are very weak.

The divergence of ORIG and innovation NEW in Figure 7 and Figure 8 shows that the proposed change is successful only in the short term, and the long-term development shows decreasing trends; if we follow the bold lines of the differences in Figs. 6, 7, we see that the effect on the target element 7 . Local infrastructure is insignificant and is limited to element 4. $T / E$ innovations. Using this strategy, the rest of the problem remains uninfluenced.

\subsection{Formation of Development STRATEGIES}

The development of strategy poses a major challenge: how to (a) formulate; and (b) prove their substantive efficiency claims and their actual economic performance. In this paper, the changes that are applied are potential - virtual - changes, and indicate appropriate time and factual elements for management intervention. Change can be understood as a composite of several factors formed by a combination of positive/negative support actions, or by the suspension/instigation of a particular action.

The management of microeconomic units is a persistent, rather unwinnable, struggle in bringing real content to actions. Most institutions develop new strategies on the basis of statistics - i.e. based on data characterizing the past. For example the World Bank 42 presents the structure of macroeconomic wealth in 124 countries on the basis of ex-post data [48 and 49. The essential technical-economic content of the wealth of is not taken into account in macroeconomics We remain uninformed about the application of new materials, physical principles, patents, etc.

Note. Moreover, the World Bank study [42] does not work with terms like: (1) prognosis, forecast, simulation, optimization, (2) town, village, municipality, community, (3) business, commerce, transport, store, etc. Terms of type (1) are future-oriented statements necessary for the creation of any change. Point (2) presents localization effects, and point (3) turns our attention to tools or changes. In other words, much research work has been dealing with macro retrospection for large territorial units [48, and discusses the past in terms of statistical data, etc. 


\section{Conclusions}

Choosing the right managerial intervention option in dynamic models (simulations) is a challenging procedure. A particular problem of this topic is that there often exist several ways of dealing with a particular problem, and there is a lack of general agreement on which enjoys management preference. The simulation example offers comparable outcomes, and enables studies of risk consequences 52 and economic impact 27. Most change is subject to an assessment of the risk impact, and the manager responsible for making a decision has to make an evaluation and take a decision within a limited time period. More support has to be introduced for management decisions, and this paper has attempted to find a realistic path for the analysis and support of decision problems [37. Early recognition of the positive effects of changes may contribute to a desired rational management solution. The dynamic of the difference data (i.e. distance, divergence, etc.) offers a chance for improvement. Establishing a basis for modelling and simulation is a maturing discipline, and now needs to have its own body of knowledge (i.e. SW tools, standards and mathematical methods).

\section{ACKNOWLEDGEMENTS}

This paper originated as part of a Faculty of Civil Engineering research project on Support for Technical-economic Management Processes;(TA CR TD020040), at the Czech Technical University in Prague, funded by the Technological Agency of the Czech Republic.

\section{LIST OF SYMBOLS}

A are set of knowledge elements as a general source of input data where for any $A \in \mathrm{A}$ there exists a factual description consisting of a verbal description of activities $U_{A}$, timing functions $D_{A}$, and volumetric descriptions $Q_{A}$

$\boldsymbol{A}^{Q}, \boldsymbol{A}^{Q^{\prime}}, \boldsymbol{A}^{Q^{\prime \prime}}, \boldsymbol{A}^{Q^{\prime \prime \prime}}, \ldots \quad$ sets of knowledge-oriented quantitative and qualitative descriptions of the knowledge elements

$\boldsymbol{P}_{\text {input }}=\left[\boldsymbol{A}, \boldsymbol{B}, \boldsymbol{X}_{0}\right]$ a model set of the processes and the structure of input data

$\boldsymbol{P}_{\text {output }}=\left[\boldsymbol{X}_{t}, \Delta \boldsymbol{X}_{t}\right]$ is the structure of the process output data

$\boldsymbol{A}=\left[a_{i j}\right] \in \boldsymbol{R}^{m \times n} \quad$ a matrix of changes of interactions per time unit, where $a_{i j}: A \in \mathrm{A}$

$\boldsymbol{B}=\left[b_{i j}\right] \in \boldsymbol{R}^{m \times n}$ is a matrix of acceleration of changes, where $b_{i j}: B \in \mathrm{A}$

$b X_{t, \Omega}$ is a state vector based on knowledge $\Omega$ as standards, where $x_{i}: A \in \mathrm{A}$ and $\xi \geq 0 ; \boldsymbol{X}_{t, \Omega}=f\left(G_{\text {int }}\left(\boldsymbol{A}, \boldsymbol{X}_{0}\right)\right)$, $i \in m$, describe standards of problem $\Omega$

$\Delta \boldsymbol{X}_{t}$ are changes of a state vector of standards for $t=$ $1,2, \ldots, T$, where $T$ is the time horizon

$G_{\text {map }}\left(\boldsymbol{A}^{Q}\right)$ a node-oriented graph that maps knowledge based on selected activities containing quantitative information

$G_{\text {int }}\left(\boldsymbol{A}, \boldsymbol{X}_{0}\right)$ an edge-oriented graph of changes $a_{i j} \in \boldsymbol{A}$ that specify causal interactions int of selected activities $A \in \boldsymbol{A}$ and their starting standards $\boldsymbol{X}_{0} \geq 0$.
$D(\mathrm{p} \| \mathrm{q}): \Omega \times \Omega \rightarrow \boldsymbol{R}$ data divergence from the starting solution $\mathrm{p}$ and the proposed solution $\mathrm{q}$ in space $\Omega$

\section{REFERENCES}

[1] Alcamo, J., Acosta-Michlik, L., Carius, A., Eierdanz, F., Klein, R., Krömker, D., Tänzler, D.: A new approach to quantifying and comparing vulnerability to drought. Regional Environmental Change, 8 (4), 2008, p. 137-149, DOI:10.1007/s10113-008-0065-5

[2] Bayes, T.: Essay towards Solving a Problem in the Doctrine of Chances. Biometrika, (reproduction of 1763 paper) 45 (3-4), 1958, p. 293-315, DOI:10.1098/rstl.1763.0053

[3] Beer S.: Decision and Control: The Meaning of Operations Research and Management Cybernetics. New York: Wiley, 1966.

[4] Beran, V., Dlask, P., Heralová, R., Berka, V.: Dynamic Time Scheduling. Prague: Academia Press, 2002.

[5] Beran, V., Dlask, P.: Management of Regional Sustainability. Prague: Academia Press, 2005.

[6] Beran, V., Dlask, P.: Risk Modified Dynamic Model Creation. Integrated Engineering Approach in Enterprise Management. Prague, CTU Press, 2000.

[7] Beran, V., Dlask, P.: Model for Environment Change Management. 8th International Built and Human Environment Research. Prague: CTU Publishing House, 58-66, 2008.

[8] Beran, V., Dlask, P.: Risk as an Externality in Quantitative and Marginal Approaches. In: "Regional Externalities" (Editor W. Heijman) Berlin Heidelberg New York: Springer, 2007, p. 255-256.

[9] Bertallanfy von L.: General Systems Theory: Foundations, Development, Applications. New York: Braziller, 1968, DOI:10.1126/science.164.3880.681

[10] Chenanavaz R.: Dynamic pricing, product and process innovation. European Journal of Operational Research, 222 (3), p. 553-557, DOI:10.1016/j.ejor.2012.05.009

[11] Demel, J.: Grafy a jejich aplikace. (Graphs and their Applications). Academia Prague, 2002. ISBN 80-200-0990-6.

[12] Dlask, P.: Modified Dynamic Model for Technically-Economical Problem Solving. Prague: CTU Press, 2000.

[13] European Community: Sixth periodic report on the social and economic situation and development of regions in the European Union. England, London, European Commission. 1999.

[14] European Community: Annual Report on Research and Technological Development Activities of the European Union in 2011. Brussels. European Commission. 2012.

[15] Forester, J., W.: Industrial dynamics. Portland Oregon: Productivity Press, 1961.

[16] Forester J., W.: Urban dynamics. Cambridge Mass: MIT Press, 1969, DOI:10.1002/ncr.4100580716

[17] Forester, J., W.: Principles of systems. Michigan: Productivity Press, 1990.

[18] Forester, J.: Dealing with Differences. New York: Oxford: University Press, 2009. 
[19] Han, J., Kamber, M.: Data Mining: Concepts and Techniques. Morgan Kaufmann, p. 114-116, 2001, DOI:10.1145/565117.565130

[20] Gottlob Frege: Begriffsschrift. 1879. Translation in Jean van Heijenoort, 1967.

[21] Heijman, W. (ed.): Regional Externalities. Berlin Heidelberg New York: Springer, 2007, DOI:10.1007/978-3-540-35484-0

[22] Holling, C., S.: Adaptive Environmental Assessment and Management. International Institute for Applied Systems Analysis. Blackburn Press, 1978.

[23] Van Heijenoort, J.: From Frege to Godel. A Source Book on Mathematical Logic, 1879-1931. Harvard University Press, 1977.

[24] Kahneman D., Tversky A.: Choice, Values, Frames. Cambridge: The Cambridge University Press, 2000, DOI:10.1037/0003-066X.39.4.341

[25] Kane J.: A Primer for a New Cross-Impact language-KSIM. Technological Forecasting and Social Change Journal, 4, 1972, p. 129-142, DOI:10.1016/0040-1625(72)90010-8

[26] Kant, I.: Kritik der reinen Vernunft. Heidelberg: Georg Weiss Verlag, 1891.

[27] Knight, F.: Risk, Uncertainty, and Profit. Boston: Houghton Mifflin, 1921.

[28] Kondratieff, N. D.: The long waves in economic life. Review of Economic Statistics, 17(6), 1935, p. 105-115.

[29] Meadows, D.: The Limits to Growth, Second Edition Revised, Signet. New York: Universe Books, 1974.

[30] OECD: Environmental Outlook to 2030. OECD ISBN 926404048X, 2008, DOI:10.1787/9789264040519-en

[31] OECD: Environmental Outlook to 2050. OECD ISBN 9789264122161, 2012, DOI:10.1787/9789264122246-en

[32] Palermo P. C., Ponzini D.: Spatial Planning and Urban Development: Critical Perspectives. Springer, Netherlands, 2010, DOI:10.1080/13563475.2013.774206

[33] Porter, M.: The competitive advantage of nations. New York, The Free Press, 1990, DOI:10.4236/jss.2014.24023

[34] Raiffa, H., Schlaifer, R.: Applied Statistical Decision Theory. Cambridge, Mass.: Harvard University Press, 1961, DOI:10.1080/00401706.1961.10489962

[35] Raiffa H.: Decision Analysis. New York: McGraw-Hill, 1968.

[36] Raiffa H.: Decision Analysis: Introductory Readings on Choices Under Uncertainty. New York: McGraw Hill, 1997.

[37] Roy B., Vincke P.: Multicriteria Analysis Survey and New Directions. European Journal of Operational Research, 8 (3), 1981, p. 207-218, DOI:10.1016/0377-2217(81)90168-5

[38] Saaty, T., L.: How to Make a Decision. The Analytic Hierarchy Project. European Journal of Operational Research, 48 (1), 1990, p. 9-26, DOI:10.1287/inte.24.6.19
[39] Solow, R.: A contribution to the theory of economic growth. The Quarterly Journal of Economics, 70 (1), 65-94, DOI:10.2307/1884513

[40] Schumpeter, J. A.: Business Cycles. New York. McGraw-Hill. 1939, DOI:10.1522/030021081

[41] Wilson, A., G.: Catastrophe Theory and Bifurcation: Application to Urban and Regional Systems. Choom Helm., London, 1981, DOI:10.1137/1024122

[42] World Bank.: The Changing Wealth of Nations : Measuring Sustainable Development in the New Millennium. World Bank. 2011, DOI:10.1596/978-0-8213-8488-6

[43] UNEP: Environmental Outlook 4: Assessment. United Nations Environment Programme. Malta: Progress Press Ltd., 2007.

[44] Valkering, P., van der Brugge, R., Offermans, A., Rijkens-Klomp, N.: Scenario analysis of perspective change to support climate adaptation: lessons from a pilot study on Dutch river management. Regional Environmental Change, 11 (2), 2011, p. 229-241, DOI:10.1007/s10113-010-0146-0

[45] Yingfang L., Keyun Q., Xingxing H.: Dissimilarity functions and divergence measures between fuzzy sets, Information Sciences, 288 (0), p.15-26, DOI:10.1016/j.ins.2014.07.052

[46] Závodná, M.: The electrification of tramways in Ostrava in 1900-1901, Acta Polytechnica, 52 (5), 2012, p. $130-132$.

[47] Ball, W. (1908). Gottfried Wilhelm Leibnitz. A Short Account of the History of Mathematics. Retrieved July 24, 2014, (2015, March 5).

http://etc.usf.edu/lit2go/218/ a-short-account-of-the-history-of-mathematics/ 5539/gottfried-wilhelm-leibnitz/

[48] Statistical Office ČR, (2015, May 5). http: //www.czso.cz/csu/2009edicniplan.nsf/p/4023-09

[49] World Economic Forum 2013, (2015, June 18). http://reports.weforum.org Home - Reports Towards the circular economy

[50] IMD - International Institute for Management Development, (2015, March 20). https://www. worldcompetitiveness.com/OnLine/App/Index.htm

[51] Malnight, T., W., Keys, T., S.: Fighting for Future Growth Beyond the BRICS, IMD, March 2014, (2015, April 5). http://www.imd.org/research/challenges/ TC018-14-growth-beyond-brics-malnight-keys.cfm

[52] World Bank. 2013. World Development Report 2014: Risk and Opportunity-Managing Risk for Development. Washington, DC: World Bank. DOI:10.1596/978-0-8213-9903-3 (2015, July 20). http://siteresources . worldbank.org/EXTNWDR2013/ Resources/8258024-1352909193861/ 8936935-1356011448215/8986901-1380046989056/ WDR-2014_Complete_Report.pdf 